\title{
Impact of Packaging and Storage on Quality of Watermelon Honey
}

\author{
Abker $\mathrm{AM}^{1 *}$, Madwi HA², Dawood $\mathrm{SY}^{3}$ and Elkhedir $\mathrm{AE}^{1}$
}

${ }^{1}$ Industrial Research and Consultancy Center (IRCC), Khartoum, Sudan

${ }^{2}$ Department of Food Science and Technology, Faculty of Agriculture, University of Khartoum, Sudan

${ }^{3}$ Agriculture Ministry, Khartoum, Sudan

\begin{abstract}
The objectives of this work were directed towards the study of the suitability of honey produced from watermelon and the impact of packaging materials and storage temperature on quality of watermelon honey. The processing operations included: boiling, filtration and concentration. The concentration was carried out using an open jacketed pan at $\left(100^{\circ} \mathrm{C}\right)$ temperature. Effects of storage temperatures $\left(35^{\circ} \mathrm{C}\right.$ and $\left.4^{\circ} \mathrm{C}\right)$ and duration $(1,2$ and 3 months) were studied for watermelon honey packaged in glass bottles and plastic jercans. The analysis involved physical properties, chemical composition (moisture, pH, TSS, ash, total sugars, reducing sugars and non-reducing sugars). It was found that there was a big difference between the percentage of honey and melon crude product; also there was a significant increase in the percentage of chemical parameters except $\mathrm{pH}$ and moisture, where there was a decrease. There were no significant differences (at $P \leq 0.05$ ) between samples of honey melon, which were packaged in glass bottles or in plastic jercans. However, there were significant differences $(a t P \leq 0.05)$ between products stored at $35^{\circ} \mathrm{C}$ and that at $4^{\circ} \mathrm{C}$. Samples that were stored at a temperature of $35^{\circ} \mathrm{C}$ showed, a low shelf stability which was reflected in the low proportion of TSS, Total sugars, non-reducing sugars.
\end{abstract}

Keywords: Honey; Quality; Watermelon

\section{Introduction}

Watermelon (Citrullus lanatus) is one of the important horticultural crops belonging to the family Cucurbitaceae. It is a native of dry parts of Africa, and it is a popular thirst-quencher during hot summer weather. Watermelon juice is proven to be a very concentrated source of carotenoid, namely lycopene [1]. When ripe, the sweet juicy pulp is eaten fresh; seeds are roasted as a snack or ground into an ingredient in oils or sauces. Juice from the red part of a watermelon contains 8 to 10 percent solids, of which 20 to 50 percent is sucrose. An edible syrup or fermented beverage can be made from the juice. Honey consists essentially of different sugars. Predominantly glucose and fructose . The color of honey varies from nearly colorless to dark brown. The consistency can be fluid, viscous or partly to entirely crystallized. The flavor and aroma vary, but usually derived from the plant origin [2]. Honey has antibacterial and antifungal properties and will not rot or ferment when stored under normal conditions. However honey can crystallize with time but crystallized honey is not damaged or defected in any way for human use.

Humans use the honey for many different purposes. Honey can be substitute for sugar in many foods. Long ago priests use honey and cake sweetened. Watermelon honey was not produced commercially in the Sudan; it is limited at home level preparation within production areas. Utilizing watermelon during production season for the production of honey will help in solving marketing problem of excess watermelon during the season, reduce watermelon losses, generate income, sustain food security, improve nutritional status and preserve watermelon by transforming it to honey [3].

The Objectives of the present study are to investigate the suitability of watermelon honey for storage and to determine the most appropriate packaging material (glass bottle or plastic jercan).

\section{Materials and Methods}

\section{Materials}

Twenty Fresh watermelons pieces were purchased from Khartoum central market with an average weight of $3.5 \mathrm{~kg}$ and had no bruises on the skin. Watermelon rinds were washed prior to water extraction. The watermelon was cut into quarters and the flesh was scooped out and cut into small cubes.

\section{Physical properties of watermelon}

The percentage of skin, flesh, water extract and honey was calculated as described by Saeed and Kattab [4].

\section{Preparation of water melon for processing}

Watermelon fruits were first weighed washed, then cleaned fruits were peeled, cut and sliced using sharp, clean, stainless steel knives, then boiled for thirty minutes, and then flirted to separate the water from insoluble solids. The raw watermelon that already boiled was based through a muslin bag (juice cloth) to increase filtration rate and hence shorten the filtration cycle, the bag was squeezed by hand.

\section{Processing of watermelon (Honey)}

The processing was carried out in the Food Research Center (FRC). Watermelon juice was concentrated at atmospheric pressure in an open jacketed pan (Model OSK1602), its capacity was about 60 liters, and its evaporation rate was $0.143 \mathrm{Kg} /$ minute. The pan was heated by home liquid gas, boiling was done slowly to evaporate the water without burning the product especially during the later stage when thick treacle was formed. The processing time was recorded when the concentration of honey reached 73 Brix.

*Corresponding author: Abker AM, Industrial Research and Consultancy Center (IRCC), Shambat- Altyar Alkadro, Khartoum, Sudan, Tel: 00249912490610; E-mail: abdeensiddig@yahoo.com

Received April 12, 2016; Accepted April 27, 2016; Published May 03, 2016

Citation: Abker AM, Madwi HA, Dawood SY, Elkhedir AE (2016) Impact of Packaging and Storage on Quality of Watermelon Honey. J Food Process Technol 7: 582. doi:10.4172/2157-7110.1000582

Copyright: ( 2016 Abker AM, et al. This is an open-access article distributed under the terms of the Creative Commons Attribution License, which permits unrestricted use, distribution, and reproduction in any medium, provided the original author and source are credited. 
Citation: Abker AM, Madwi HA, Dawood SY, Elkhedir AE (2016) Impact of Packaging and Storage on Quality of Watermelon Honey. J Food Process Technol 7: 582. doi:10.4172/2157-7110.1000582

Page 2 of 4

\section{Chemical evaluation methods}

Total soluble solids (TSS): Total soluble solids (TSS) were determined at room temperature using digital refractometer with degree ${ }^{\circ}$ Brix scale $0-100$ according to AOAC [5]

pH-value: The $\mathrm{pH}$ was determined using a $\mathrm{pH}$-meter (model $\mathrm{HI}$ 8521 microprocessor bench $\mathrm{pH} / \mathrm{MV} / \mathrm{C}^{\circ}$ meter). Two standard buffer solution of $\mathrm{pH} 4.00$ and 7.00 were used for calibration of the $\mathrm{pH}$ meter at room temperature. The $\mathrm{pH}$ meter was allowed to stabilize for one minute and then the $\mathrm{pH}$ of the samples was directly measured.

Reducing and total sugars: The reducing and total sugars were determined according to the method described by Schneider [6]

Sucrose (\%): The sucrose (\%) was determined by the following equation:

Sucrose $(\%)=$ Total sugars - Reducing sugars $\times 0.95$

Moisture content: The moisture content of the sample was determined according to the modified method of AOAC [5].

Ash content: The ash content of the sample was determined according to the AOAC [5].

Statistical analysis: The data were subjected to Statistical Analysis System (SAS) Software and Randomized Complete Design (RCD) was used with factorial design and then means separated according to Gomez and Gomez [7]

\section{Results and Discussion}

\section{Physical properties of watermelon}

Table 1 shows the percentage of skins, flesh and seeds, juice extract

\begin{tabular}{|c|c|c|c|}
\hline Skin (\%) & $\begin{array}{c}\text { Flesh and seeds } \\
(\%)\end{array}$ & $\begin{array}{c}\text { Flesh and seeds } \\
(\%)\end{array}$ & Honey (\%) \\
\hline 33.5 & 45.2 & 45.2 & 5.3 \\
\hline
\end{tabular}

Table 1: Physical properties of watermelon. and honey in relation to the whole fruit weight. These were skins (33.5\%), flesh and seeds (45.2\%), water extract (16\%) and honey (5.3\%).

\section{The chemical characteristics of watermelon before and after processing}

Table 2 shows comparison between the chemical composition of watermelons before and after processing, as shown in the Table, there were decrease in moisture content and $\mathrm{pH}$, and increase in total soluble solids, ash, total sugars, reducing sugars and non-reducing sugars.

\section{Effect of storage conditions on the properties of watermelon honey}

The watermelon honeys have been packaged in two different packaging materials i.e., plastic jercan and glass bottles and then were stored at two different temperature i.e., $35^{\circ} \mathrm{C}$ (room temperature) and $4^{\circ} \mathrm{C}$ (domestic refrigerator), for three months.

\section{Total soluble solids of watermelon honey (TSS)}

Table 3 shows total soluble solids, there is a significant differences (at $\mathrm{P} \leq 0.05$ ) for decrease in T.S.S. during storage periods temperature for the two packaging materials. Glass bottle reported $70.60 \%$ at the end of storage while plastic jercans $71.30 \%$. This can be attributed to the concentration of some soluble solids during storage [8].

\section{Total sugars of watermelon honey}

Table 4 shows the total sugars (\%) during storage periods at different storage temperatures. There are significant differences $(P \leq 0.05)$. The total sugars of watermelon honey at refrigerator temperature and room temperature, packaged in glass bottle after one month decreased but increased at 2 months and 3 months, storage period to higher levels $53.06 \%$ (room temperature) and 54.90\% (refrigerator) respectively.

Whereas watermelon honey stored at room temperature and refrigerator, packaged in plastic jercan were decreased after one month

\begin{tabular}{|c|c|c|c|c|c|c|}
\hline TSS (\%) & Total Sugar (\%) & Reducing Sugars (\%) & Non Reducing sugar (\%) & pH & Moisture (\%) & 5.5 \\
\hline 7.2 & 5.1 & 4.51 & 0.55 & 91.86 & 4.94 \\
\hline 73.4 & 48.73 & 35.88 & 12.53 & 0.13 & 27.2 \\
\hline
\end{tabular}

Table 2: Chemical composition of watermelon before and after processing.

\begin{tabular}{|c|c|c|c|c|c|c|c|c|}
\hline \multirow[t]{4}{*}{ Type of container } & \multicolumn{8}{|c|}{ Temperature } \\
\hline & \multicolumn{4}{|c|}{ Room } & \multicolumn{4}{|c|}{ Refrigerator } \\
\hline & \multicolumn{8}{|c|}{ Storage period (month) } \\
\hline & 0 & 1 & 2 & 3 & 0 & 1 & 2 & 3 \\
\hline Glass bottle & $73.40^{\mathrm{a}}( \pm 0.04)$ & $70.90^{\mathrm{e}}( \pm 0.02)$ & $70.40^{\mathrm{h}}( \pm 0.02)$ & $70.60^{9}( \pm 0.02)$ & $73.40^{\mathrm{a}}( \pm 0.04)$ & $71.00^{d}( \pm 0.03)$ & $70.40^{\mathrm{h}}( \pm 0.02)$ & $70.20^{i}( \pm 0.02)$ \\
\hline Plastic jercan & $73.40^{\mathrm{a}}( \pm 0.04)$ & $70.70^{f}( \pm 0.02)$ & $69.40^{k}( \pm 0.01)$ & $71.20^{\circ}( \pm 0.03)$ & $73.40^{\mathrm{a}}( \pm 0.04)$ & $69.70^{\mathrm{j}}( \pm 0.01)$ & $71.00^{d}( \pm 0.03)$ & $71.30^{\mathrm{b}}( \pm 0.03)$ \\
\hline Lsd 0.05 & \multicolumn{8}{|c|}{$0.0005259^{*}$} \\
\hline $\mathrm{SE} \pm$ & \multicolumn{8}{|c|}{0.0001826} \\
\hline
\end{tabular}

Mean \pm SD value(s) bearing different superscript(s) within columns and rows (interactions) are significantly different (P $\leq 0.05)$

Table 3: Effect of storage temperature and packaging materials on total soluble solids of watermelon honey over period of three months.

\begin{tabular}{|c|c|c|c|c|c|c|c|c|}
\hline \multirow[t]{4}{*}{ Type of container } & \multicolumn{8}{|c|}{ Temperature } \\
\hline & \multicolumn{4}{|c|}{ Room } & \multicolumn{4}{|c|}{ Refrigerator } \\
\hline & \multicolumn{8}{|c|}{ Storage period (month) } \\
\hline & 0 & 1 & 2 & 3 & 0 & 1 & 2 & 3 \\
\hline Glass bottle & $48.73^{e}( \pm 1.13)$ & $47.33^{f}( \pm 1.18)$ & $53.40^{\mathrm{b}}( \pm 1.58)$ & $53.06^{b}( \pm 1.51)$ & $48.73^{e}( \pm 1.13)$ & $42.72^{i}( \pm 1.09)$ & $51.14^{\mathrm{d}}( \pm 1.53)$ & $50.98^{d}( \pm 1.49)$ \\
\hline Plastic jercan & $48.73^{e}( \pm 1.13)$ & $45.4^{\mathrm{h}}( \pm 1.21)$ & $54.80^{\mathrm{a}}( \pm 1.61)$ & $54.90^{\mathrm{a}}( \pm 1.62)$ & $48.73^{e}( \pm 1.13)$ & $46.36^{g}( \pm 1.18)$ & $52.06^{c}( \pm 1.54)$ & $52.09^{c}( \pm 1.50)$ \\
\hline Lsd 0.05 & \multicolumn{8}{|c|}{$0.4141^{*}$} \\
\hline SE \pm & \multicolumn{8}{|c|}{0.1438} \\
\hline
\end{tabular}

Mean \pm SD value(s) bearing different superscript(s) within columns and rows (interactions) are significantly different (P $\leq 0.05)$

Table 4: Effect of storage temperature and packaging materials on total sugars of watermelon honey over period of three months. 
Citation: Abker AM, Madwi HA, Dawood SY, Elkhedir AE (2016) Impact of Packaging and Storage on Quality of Watermelon Honey. J Food Process Technol 7: 582. doi:10.4172/2157-7110.1000582

Page 3 of 4

but increased after 2 months and 3 months to higher levels $50.98 \%$ (room temperature) and $52.09 \%$ (refrigerator) respectively. This decrease and increase of total sugars may be due to inversion of sucrose to glucose and fructose sugars during storage time [7]. The production of invert sugars may cause non enzymic browning.

\section{Reducing sugars of watermelon honey}

Table 5 shows high significant differences (at $\mathrm{P} \leq 0.05$ ) in content of reducing sugars during storage time. The glass bottles stored at room temperature reported $(35.88 \%, 31.72 \%, 40.78 \%$ and $44.36 \%)$ and that stored in refrigerator recorded $(35.88 \%, 29.60 \%, 45.10 \%$ and $45.10 \%)$ they decreased after one month and increased after 2 and 3months.

Reducing sugars in plastic jercan stored at room temperature and refrigerator decreased after one month $(32.36 \%$ and $31.63 \%)$. Then increased after 2 and 3 months gradually $(42.46 \%, 43.34 \%, 39.86 \%$ and $39.70 \%$ ). This decrease and increase may be due to non-enzymatic browning reactions Hulme [9] reported that many interactions are possible in fruit juice concentrates, notably between sugars, organic acids, nitrogenous components and phenol compounds, the change being greatest at higher temperature of storage.

\section{Non reducing sugars of watermelon honey}

Table 6 Shows, that there are significant differences (at $\mathrm{P} \leq 0.05)$ in non-reducing sugars content values. They were found to range between $(14.83 \%, 11.99 \%, 8.34 \%, 12.46 \%, 5.74 \%$ and $5.59 \%$ in glass bottles and
$12.39 \%, 11.72 \%, 10.98 \%, 13.68 \%, 11.61 \%$ and $12.07 \%$ in plastic jercans) at $35^{\circ} \mathrm{C}$ and $4^{\circ} \mathrm{C}$, respectively. The results obtained shows gradually decrease during storage periods; this could be due to the inversion of sucrose with notably slightly increased in plastic jercan stored in refrigerator after 3 months of storage. This could be due to container.

\section{pH of watermelon honey}

Table 7 shows $\mathrm{pH}$ values, there is a significant difference at $(\mathrm{P} \leq$ 0.05 ) during storage periods; the high level of $\mathrm{pH}$ was at glass bottles stored at refrigerator.

\section{Moisture content of watermelon honey}

Table 8 Shows the moisture content (\%) during storage periods at different storage temperatures. There are significant differences (at $\mathrm{P} \leq$ $0.05)$ decrease in moisture content of watermelon honey. This could be due to evaporation and concentration of water during storage.

\section{Ash content of watermelon honey}

Table 9 shows ash content; there is a significant difference (at $\mathrm{P} \leq$ 0.05 ) in ash content during storage periods at both storage temperatures and package containers of watermelon honey.

\section{Conclusion}

From the interpretation of the results obtained in this study it can be concluded that Watermelon showed suitability in processing to give watermelon honey and there was increase in total sugars most of time

\begin{tabular}{|c|c|c|c|c|c|c|c|c|}
\hline \multirow[t]{4}{*}{ Type of container } & \multicolumn{8}{|c|}{ Temperature } \\
\hline & \multicolumn{4}{|c|}{ Room } & \multicolumn{4}{|c|}{ Refrigerator } \\
\hline & \multicolumn{8}{|c|}{ Storage period (month) } \\
\hline & 0 & 1 & 2 & 3 & 0 & 1 & 2 & 3 \\
\hline Glass bottle & $35.8^{9}( \pm 1.17)$ & $31.7^{\prime}( \pm 1.11)$ & $40.78^{\mathrm{e}}( \pm 1.23)$ & $44.36^{b}( \pm 1.35)$ & $35.88^{9}( \pm 1.17)$ & $29.60^{j}( \pm 1.07)$ & $45.10^{\mathrm{a}}( \pm 1.37)$ & $45.10^{\mathrm{a}}( \pm 1.37)$ \\
\hline Plastic jercan & $35.8^{g}( \pm 1.17)$ & $32.36^{h}( \pm 1.13)$ & $42.46^{d}( \pm 1.31)$ & $43.34^{\mathrm{c}}( \pm 1.32)$ & $35.88^{g}( \pm 1.17)$ & $31.63^{i}( \pm 1.12)$ & $39.86^{f}( \pm 1.22)$ & $39.70^{f}( \pm 1.20)$ \\
\hline Lsd 0.05 & \multicolumn{8}{|c|}{$0.2467^{* *}$} \\
\hline $\mathrm{SE} \pm$ & \multicolumn{8}{|c|}{0.08563} \\
\hline
\end{tabular}

Table 5: Effect of storage temperature and packaging materials on reducing sugars of watermelon honey over period of three months.

\begin{tabular}{|c|c|c|c|c|c|c|c|c|}
\hline \multirow[t]{4}{*}{ Type of container } & \multicolumn{8}{|c|}{ Temperature } \\
\hline & \multicolumn{4}{|c|}{ Room } & \multicolumn{4}{|c|}{ Refrigerator } \\
\hline & \multicolumn{8}{|c|}{ Storage period (month) } \\
\hline & 0 & 1 & 2 & 3 & 0 & 1 & 2 & 3 \\
\hline Glass bottle & $12.53^{\mathrm{c}}( \pm 0.97)$ & $14.83^{\mathrm{a}}( \pm 1.10)$ & $11.99^{d}( \pm 1.09)$ & $8.34^{g}( \pm 0.65)$ & $12.53^{c}( \pm 0.97)$ & $12.46^{\circ}( \pm 0.97)$ & $5.74^{\mathrm{h}}( \pm 0.33)$ & $5.59^{\mathrm{h}}( \pm 0.31)$ \\
\hline Plastic jercan & $12.53^{\mathrm{c}}( \pm 0.97)$ & $12.39^{\circ}( \pm 1.08)$ & $11.72^{\mathrm{e}}( \pm 1.07)$ & $10.98^{f}( \pm 0.91)$ & $12.53^{c}( \pm 0.97)$ & $13.68^{\mathrm{b}}( \pm 1.02)$ & $11.61^{\mathrm{e}}( \pm 1.06)$ & $12.07^{d}( \pm 0.94)$ \\
\hline Lsd 0.05 & \multicolumn{8}{|c|}{$0.2292^{*}$} \\
\hline SE \pm & \multicolumn{8}{|c|}{0.07958} \\
\hline
\end{tabular}

Table 6: Effect of storage temperature and packaging materials on Non-reducing sugars of watermelon honey over period of three months.

\begin{tabular}{|c|c|c|c|c|c|c|c|c|}
\hline \multirow[t]{4}{*}{ Type of container } & \multicolumn{8}{|c|}{ Temperature } \\
\hline & \multicolumn{4}{|c|}{ Room } & \multicolumn{4}{|c|}{ Refrigerator } \\
\hline & \multicolumn{8}{|c|}{ Storage period (month) } \\
\hline & 0 & 1 & 2 & 3 & 0 & 1 & 2 & 3 \\
\hline Glass bottle & $4.94^{a}( \pm 0.36)$ & $4.72^{\mathrm{d}}( \pm 0.31)$ & $4.51^{\mathrm{j}}( \pm 0.25)$ & $4.58^{\mathrm{h}}( \pm 0.27)$ & $4.94^{\mathrm{a}}( \pm 0.36)$ & $4.71^{\mathrm{e}}( \pm 0.29)$ & $4.55^{i}( \pm 0.24)$ & $4.62^{f}( \pm 0.28)$ \\
\hline Plastic jercan & $4.94^{\mathrm{a}}( \pm 0.36)$ & $4.76^{\mathrm{b}}( \pm 0.31)$ & $4.61^{g}( \pm 0.28)$ & $4.75^{\mathrm{c}}( \pm 0.30)$ & $4.94^{\mathrm{a}}( \pm 0.36)$ & $4.76^{b}( \pm 0.31)$ & $4.61^{\mathrm{g}}( \pm 0.28)$ & $4.75^{\mathrm{c}}( \pm 0.32)$ \\
\hline Lsd 0.05 & \multicolumn{8}{|c|}{$0.0005259^{*}$} \\
\hline $\mathrm{SE} \pm$ & \multicolumn{8}{|c|}{0.0001826} \\
\hline
\end{tabular}

Table 7: Effect of storage temperature and packaging materials on $\mathrm{pH}$-value of watermelon honey over period of three months. 
Citation: Abker AM, Madwi HA, Dawood SY, Elkhedir AE (2016) Impact of Packaging and Storage on Quality of Watermelon Honey. J Food Process Technol 7: 582. doi:10.4172/2157-7110.1000582

Page 4 of 4

\begin{tabular}{|c|c|c|c|c|c|c|c|c|}
\hline \multirow[t]{4}{*}{ Type of container } & \multicolumn{8}{|c|}{ Temperature } \\
\hline & \multicolumn{4}{|c|}{ Room } & \multicolumn{4}{|c|}{ Refrigerator } \\
\hline & \multicolumn{8}{|c|}{ Storage period (month) } \\
\hline & 0 & 1 & 2 & 3 & 0 & 1 & 2 & 3 \\
\hline Glass bottle & $27.20^{\mathrm{a}}( \pm 1.25)$ & $25.07^{b}( \pm 1.23)$ & $23.72^{\mathrm{c}}( \pm 1.19)$ & $24.87^{\mathrm{b}}( \pm 1.22)$ & $27.20^{\mathrm{a}}( \pm 1.25)$ & $24.51^{\mathrm{bc}}( \pm 1.21)$ & $24.38^{b} c( \pm 1.19)$ & $24.92^{\mathrm{b}}( \pm 1.23)$ \\
\hline Plastic jercan & $27.20^{\mathrm{a}}( \pm 1.25)$ & $24.4 b^{c}( \pm 1.21)$ & $24.42^{\mathrm{bc}}( \pm 1.21)$ & $24.76^{b}( \pm 1.22)$ & $27.20^{\mathrm{a}}( \pm 1.25)$ & $24.45^{\mathrm{bc}}( \pm 1.20)$ & $24.22^{\mathrm{bc}}( \pm 1.17)$ & $24.46^{\text {bc }}( \pm 1.20)$ \\
\hline Lsd 0.05 & \multicolumn{8}{|c|}{$0.8464^{*}$} \\
\hline SE \pm & \multicolumn{8}{|c|}{0.2938} \\
\hline
\end{tabular}

Table 8: Effect of storage temperature and packaging materials on Moisture content of watermelon honey over period of three months.

\begin{tabular}{|c|c|c|c|c|c|c|c|c|}
\hline \multirow[t]{4}{*}{ Type of container } & \multicolumn{8}{|c|}{ Temperature } \\
\hline & \multicolumn{4}{|c|}{ Room } & \multicolumn{4}{|c|}{ Refrigerator } \\
\hline & \multicolumn{8}{|c|}{ Storage period (month) } \\
\hline & 0 & 1 & 2 & 3 & 0 & 1 & 2 & 3 \\
\hline Glass bottle & $1.580^{\text {bcde }}( \pm 0.45)$ & $1.810^{\mathrm{ab}}( \pm 0.49)$ & $1.730^{\text {abcd }}( \pm 0.46)$ & $1.610^{\text {abcde }}( \pm 0.45)$ & $1.580^{\text {bcde }}( \pm 0.45)$ & $1.423^{\mathrm{e}}( \pm 0.41)$ & $1.493^{\text {cde }}( \pm 0.45)$ & $1.777^{\mathrm{ab}}( \pm 0.42)$ \\
\hline Plastic jercan & $1.580^{\text {bcde }}( \pm 0.45)$ & $1.743^{\mathrm{abc}}( \pm 0.47)$ & $1.470^{\text {de }}( \pm 0.44)$ & $1.447 \mathrm{e}( \pm 0.44)$ & $1.580^{\text {bcde }}( \pm 0.45)$ & $1.857^{\mathrm{a}}( \pm 0.50)$ & $1.447^{e}( \pm 0.43)$ & $1.467^{\text {de }}( \pm 0.43)$ \\
\hline Lsd 0.05 & \multicolumn{8}{|c|}{$0.2352^{*}$} \\
\hline $\mathrm{SE} \pm$ & \multicolumn{8}{|c|}{0.08165} \\
\hline
\end{tabular}

Table 9: Effect of storage temperature and packaging materials on Ash content of watermelon honey over period of three months.

during storage time. The best storage condition should be Packaging in tightly sterilized glass bottles or plastic jerkins.

\section{Acknowledgment}

The authors express their sincere gratitude and thanks to the staff and technicians of The Food Research Centre-Shambat for their valuable and unlimited assistance which they presented during implementation of the research.

\section{References}

1. Edwards AJ, Vinyard BT, Wiley ER, Brown ED, Collins JK, et al. (2003) Consumption of watermelon juice increases plasma concentrations of lycopene and beta-carotene in humans. J Nutr 133: 1043-1050.

2. Codex Alimentarius Commission (1994) Codex Standard for Honey. Ref 11: 21-24.

3. Baker AM (2012) Personal Communication.
4. Saeed A, Kattab A (1974) Suitability of Mango Cultivar for nectar manufacture. Journal of food since and technology. 6: 24-31.

5. AOAC (1984) Official methods of analysis. Association of Official Analytical Chemist. Washington DC, USA.

6. Schneider JM, Curet LB, Olson RW, Schneider JM, Zachman RD (1979) Effect of diabetes mellitus on amniotic fluid lecithin/sphingomyelin ratio and respiratory distress syndrome. Am J Obstet Gynecol 135: 10-13.

7. Gomez A, Gomez AA (1984) Statistical procedure for agriculture research (2ndedn). John Wiley and Sons.

8. Herschdoereer SM (1972) Food Science and Technology: Quality Control in the Food Industry. Academic press, London.

9. Hulme AC (1971) Biochemistry of fruits and their products. Academic press London. 